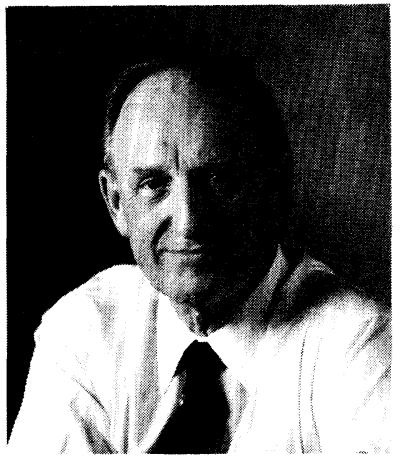

\section{A Specific Question of Ethics}

I have not really taken much time in my editorials to discuss ethical behavior by authors, reviewers, and editors, other than the December editorial in 1992 (Vol. 31,No. 12, p.2517). However, a recent experience has moved me to action.

In general, people in our field of optical science and engineering behave very responsibly and ethically and we have very few horror stories, unlike those that are reported to me by editors in other fields. The only problem that I have encountered is the issue of authors submitting their papers to two or more journals at the same time. I have had to deal with a handful of these cases over the last five years. Even though rare occurrences for us in Optical Engineering, they are disturbing when they happen.

The specific case that I would like to use in this editorial, without any names, started when Managing Editor Mohan Nair received the following letter on August 9, 1995.

\section{Dear Mr. Mohan Nair,}

I regret to inform you that we have decided to withdraw the paper entitled ". "Therefore, I would like to ask you to do not publish the paper. I am sorry for the inconvenience that I might have caused.

Yours sincerely,

Both Mohan and I were concerned by this withdrawal since the paper in revised form had been accepted in the middle of May and was in the process of being published. The history of this paper was that it had been received in late 1994, reviewed, and returned to the authors for revision. The revised manuscript was received in late April, re-reviewed, and accepted. We do understand, of course, that there are legitimate reasons for withdrawing a paper.

I did write a letter to the author on August 18, in which I said "I just received a copy of your message about the withdrawal of your paper. We will, of course, not publish your paper, hence I would like to know why you decided to withdraw it at the last minute." You can imagine my surprise when I received the following letter dated August 31.

\section{Dear Dr. Thompson,}

We have decided to withdraw the paper due to it has been published in another Journal. As soon as we received the notification that the paper would be published in the other Journal, I wrote to Mr. Mohan Nair.

That is why, I just wrote at the last minute.
I am very sorry for the inconvenience that we might have caused.

I apologize.

Yours sincerely,

To conclude this story, I reprint the response that I made to the author on September 18.

\section{Dear}

I received your letter and note that you have withdrawn your paper from consideration by Optical Engineering.

You should be aware that it is considered unethical to submit a paper to more than one journal at the same time, as you appear to have done. Many journals ask for a statement from the authors that they have not submittted the paper to another journal; other journals require that the copyright be assigned to the journal before the review process is conducted. Optical Engineering does not require this since we prefer to rely on the integrity of the authors.

Sincerely,

I have heard nothing further from the author!

\section{Editor's Anecdote}

Happily for your editor, the previous story represents a very small minority of the colleagues that I work with every day. So, to balance this editorial, I share with you, again anonymously, a letter that certainly made me feel good.

\footnotetext{
“...sometime ago you had sent me a paper to review (followed by a reminder). I put it among a pile of things to do. I had been going through a lengthy period of personal disorganization and never got around to responding. I apologize for my very inconsiderate behavior and hope I did not cause you too much inconvenience.

You probably do not remember me but I took a class from you (in Physical Optics) at the University of Rochester when I first came to this country. It seems I was late for class every morning. Every morning that is, until the last class, a review class for which, due to a misunderstanding, I arrived an hour early. I hadn't realized the regularity of my tardiness until at the end of that last class you announced that you were particularly disappointed in me for ruining my record for being late for every single class. It seems I have not changed a great deal. In spite of my tardiness, I have fond memories of that class. You were one of the best instructors I have ever had and listening to your lectures was always a pleasure. Thank you.

Sincerely,
} 
January 1996

Optical Science and Engineering in Argentina

Guillermo H. Kaufmann

Universidad Nacional de Rosario

Instituto de Fisica Rosario

Applied Optics Group

Bv. 27 de Febrero 210 bis

2000 Rosario

Argentina

E-mail: guille@ifir.edu.ar

or gkaufman@arosario.bitnet

5441825838 • 5441257164 FAX

Visual Communications

and Image Processing

Cheng-Tie Chen

Bellcore, NVC 3X-321

331 Newman Springs Road

Red Bank, NJ 07701

908/758-3106 • 908/758-4371 FAX

E-mail: ctc@nyquist.bellcore.com

Kou-Hu Tzou

COMSAT Laboratories

22300 Comsat Drive

Clarksburg, MD 20871

301/428-4663 • 301/428-9287 FAX

E-mail: kouhu@ctd.comsat.com

Ya-Qin Zhang

David Sarnoff Research Center

201 Washington Road

Princeton, NJ 08543-5300

609/734-2095 • 609/734-2049 FAX

E-mail: zhang@earth.sarnoff.com

\section{February 1996}

Optical Engineering in Small Companies

Xiangyang Yang

University of New Orleans

Department of Electrical Engineering

New Orleans, LA 70148

504/286-5524 • 504/286-3950

E-mail: xxyee@uno.edu
William J. Miceli

Office of Naval Research

800 North Quincy Street

Arlington, VA 22217-5000

703/696-5752 • 703/696-1330 FAX

\section{March 1996}

\section{Sensor Fusion}

Belur V. Dasarathy

Dynetics, Inc.

P.O. Box Drawer B

Huntsville, AL 35814-5050

205/922-9230 ext. $355 \cdot 205 / 922-9219$ or

205/922-9260 FAX

E-mail: belur@dynetics.com

\section{May 1996}

\section{Optical Engineering in Romania}

Adrian Podoleanu

University of Kent at Canterbury

Physics Laboratory

Kent CT2 7NR

United Kingdom

0227764000 • 0227475423 FAX

E-mail: ap11@ukc.ac.uk

\section{June 1996}

\section{Electronic Holography}

Chung J. Kuo

National Chung Cheng University Department of Electrical Engineering

Chiayi, Taiwan 62107

88652720862 FAX

E-mail: kuo@ee.ccu.edu.tw

July 1996

\section{Optical Security}

Joseph L. Horner

Rome Laboratory

Department of the Air Force

Hanscom AFB, MA 01731

617/377-3841 • 617/377-2836 FAX

E-mail: horner@eastlouex.rl.af.mil
Bahram Javidi

University of Connecticut

Electrical and Systems Engineering

Department

U-157, Room 312, Eng. III

260 Glenbrook Road

Storrs, CT 06269

203/486-2867 • 203/486-0318 FAX

E-mail: bahram@eng2.uconn.edu

\section{August 1996}

\section{Applications of Neural Networks in Optics}

Suganda Jutamulia

Kowa Company, Ltd.

100 Century Center Court

Suite 302

San Jose, CA 95112-4512

408/441-9300 • 408/441-0537 FAX

Francis T. S. Yu

The Pennsylvania State University

Electrical and Computer Engineering

Department

216 Electrical Engineering East

University Park, PA 16802

814/863-2989 • 814/865-7065 FAX

E-mail: dapece@engr.psu.edu

Toshimitsu Asakura

Hokkaido University

Research Institute for Electronic Science

Kita 12, Nishi-6

Kita-ku, Sapporo 060 Japan

81117162111 ext. $2877 \cdot 81117583173$

FAX

E-mail: asakura@hikari.hokudai.ac.jp

Manuscripts due Jan. 1, 1996 